\title{
Modelo Curricular UTEC
}

\author{
José Adolfo Araujo \\ Jesús Marcos Soriano \\ Adbélica Luna \\ Oscar Melgar \\ Fernando Burgos
}

\section{INTRODUCCIÓN}

Se presenta una síntesis del modelo curricular UTEC, para su difusión entre toda la comunidad educativa, así como los interesados en estimar el rumbo académico de nuestra universidad.

Contiene un marco institucional, el concepto, las características y los valores institucionales del modelo.

\section{A. PROPÓSITO.}

Formar profesionales de calidad, con las competencias y valores que demanda la sociedad.

\section{B. MARCO INSTITUCIONAL.}

La Universidad Tecnológica, como institución de educación superior, ha experimentado una transformación curricular de acuerdo con su MISIÓN Y VISIÓN; ha realizado un análisis permanente de su oferta educativa y ha modificado la organización académica, para dar respuestas más efectivas a los requerimientos de formación profesional, planteadas por diferentes sectores: empleadores, gremiales y profesionales.

La Visión y la Misión de la universidad han sido formuladas con la participación y consenso del Directorio Ejecutivo. Estas plantean lo siguiente:
VISIÓN: "Ser reconocida como una de las mejores universidades privadas de la región, a través de sus egresados y de sus esmerados procesos institucionales de construcción y aplicación del conocimiento, proponiendo soluciones pertinentes a las necesidades de amplios sectores de la sociedad."

MISIÓN: "La Universidad Tecnológica de El Salvador existe para brindar a amplios sectores poblacionales, innovadores servicios educativos, promoviendo su capacidad crítica y su responsabilidad social; utilizando metodologías y recursos académicos apropiados; desarrollando institucionalmente: investigación pertinente y proyección social, todo consecuente con su filosofía y legado cultural."

La Universidad Tecnológica ha dado seguimiento a las estrategias y políticas nacionales e internacionales que, en materia de educación, han sido reconocidas y aceptadas y, para dar respuesta a ellas, se ha preparado y ha participado de manera voluntaria, en los diferentes procesos de acreditación en el ámbito nacional e internacional: MINED, RLCU Y AUPRICA, logrando en cada proceso, el reconocimiento de calidad como institución acreditada. Esto le ha propiciado las condiciones para enfrentar una sociedad, que se perfila cada vez más compleja, competitiva y globalizada. 
Consciente de su responsabilidad con la sociedad, la Universidad Tecnológica ha fundamentado las bases para un proceso de formación e información cada vez más comprometido con el desarrollo del conocimiento y la era de la creatividad. Ha incorporado nuevas estrategias técnicocientíficas, que permiten a la comunidad universitaria acceder de manera multivariada a la realidad. Asimismo, ha integrado sus esfuerzos con otras instituciones nacionales e internacionales, mediante convenios que le permiten implementar aquellas acciones, que responden a las exigencias de los nuevos escenarios informáticos y tecnológicos que debe enfrentar el nuevo profesional. Para dar soporte a lo anterior, la Universidad ha realizado convenios con INCAE, Taiwán, Universidad de Granada y otras, no menos importantes, que le permiten a la currícula de la universidad consolidar experiencias con mayor solidez científica.

La UTEC continúa realizando de manera sistemática, la actualización de su oferta educativa. En la actualidad está introduciendo el enfoque de formación por competencias en forma progresiva, ciclo por ciclo, hasta completar todas las carreras que ofrece.

El nuevo Modelo Curricular UTEC plantea, como elemento central de la currícula, la formulación del perfil profesional por competencias, los métodos y técnicas que propician el acto educativo de manera participativa, creativa y constructiva; el alcance de los objetivos de aprendizaje basados en competencias y hace énfasis en la aplicación de un sistema de evaluación de carácter individual y grupal, con propósitos diagnóstico, formativo y sumativo. Todo este tratamiento curricular responde a las necesidades reales, de un mundo que evoluciona a un ritmo muy acelerado.

En síntesis, el marco referencial que da soporte al carácter institucional de la UTEC, como concepto y en un sentido amplio, se refiere a un "remirar" el proceso curricular en todas sus fases: investigación, diseño, implementación y evaluación. En este contexto, el proceso de revisión curricular desarrolla un modelo curricular ecléctico, que combina el enfoque academicista por asignaturas con el enfoque de formación por competencias.

La universidad se ha identificado con valores universales para formar el marco ético institucional que determine la praxis cotidiana de su comunidad educativa.
La formación universitaria debe asegurar al profesional el desarrollo de los siguientes valores:

- Compromiso agresivo (responsabilidad)

- Innovación permanente.

- Responsabilidad y pensamiento positivo.

- Liderazgo institucional.

- Solidaridad y transcendencia cultural.

- Integridad.

- Trascendencia.

Lo anterior determina una serie de principios, que se han venido desarrollando y se deberán mantener como referentes del desarrollo curricular.

\section{MODELO CURRICULAR UTEC/2011.}

\section{CONCEPTO.}

Este modelo considera las ventajas tanto del modelo academicista como del modelo de formación por competencias, haciendo énfasis en el rol protagónico del estudiante en el desarrollo del proceso de enseñanza- aprendizaje, para lograr un propósito claro y definido. El docente es un mediador, constructor, motivador, aprendedor y trasformador de los procesos de aprendizaje; el estudiante es un ser activo, constructor de su propio aprendizaje en función de sus propios intereses y los de la sociedad.

\section{CARACTERÍSTICAS.}

El modelo curricular propicia la interacción entre el sistema educativo y su entorno, integrando las influencias externas en el propio proceso curricular abierto a un constante sistema de revisión y reorganización.

Un componente importante del modelo curricular adoptado por la UTEC, es la formulación por competencias del perfil profesional del graduado; el cual está conformado por tres perfiles: general, básico y de especialidad.

El perfil general está conformado por las competencias que debe mostrar el graduado de la Universidad tecnológica al finalizar su carrera, convirtiéndose en una huella distintiva de su alma mater. Dicho perfil está constituido por las siguientes competencias: 
- Comunicar profesionalmente las ideas en forma oral y escrita.

- Utilizar las tecnologías de la información y comunicación (TIC'S).

- Construir un plan de desarrollo personal.

- Tomar decisiones con fundamentos técnicos.

- Innovar y ser agente de cambio promoviendo la cultura y la conservación del medio ambiente.

- Analizar los procesos globalizadores para enfrentar los cambios.

- Interpretar textos básicos y vocabulario técnico en el idioma inglés.

- Practicar una vida digna y respetable en la sociedad a través de la ilustración y solidaridad.

- Contribuir a la construcción del conocimiento.

- Actualizar sus conocimientos en forma permanente.

El perfil básico está conformado por un conjunto de competencias que le permiten al graduado, desempeñarse con propiedad en diferentes áreas de trabajo; aun no siendo de su especialidad.

El perfil de especialidad comprende todas aquellas competencias que le permiten al graduado desempeñarse con seguridad, calidad, eficiencia y competitividad, en un área profesional específica.

El modelo curricular UTEC/2011 tiene características propias, que lo identifican y distinguen de cualquier otro intento anterior de introducir la formación por competencias, y son las siguientes:

- Cada plan de estudios se diseña con todos los componentes curriculares: perfil profesional (general, básico y de especialidad), pensum, programas de estudio y sistema de evaluación.

- Formula el perfil profesional en términos de competencias.

- Deriva el perfil profesional de las necesidades del mundo laboral y de la sociedad en general.

- Mantiene el diseño por asignaturas, asignándole a cada una, las competencias que se pueden lograr en un ciclo de estudios.

- Organiza cada programa de estudios en unidades de aprendizaje, las cuales deben desarrollar las competencias respectivas.
- Garantiza, en cada asignatura, la adecuada combinación de la teoría con la práctica.

- Elimina las secuencias de prerrequisitos innecesarios entre las asignaturas.

- Garantiza al educando como principal actor del proceso enseñanza-aprendizaje.

- Aplica la evaluación con propósitos: diagnóstico, formativo y sumativo.

- Adecua la escala de evaluación de cero a diez, al dominio de competencias.

- Aprueba estudiantes, en función del dominio de competencias.

- Asegura la evaluación de competencias.

- Facilita la aplicación de una variedad de métodos de enseñanza aprendizaje.

\section{ESTRATEGIA.}

Para la implementación del Modelo Curricular UTEC 2011, se ha considerado conveniente ejecutar cuatro proyectos, algunos simultáneos por la interacción de sus actividades:

- Capacitación.

- Diseño curricular.

- Implementación y ejecución.

- Seguimiento, control y evaluación.

En el proceso de capacitación, el personal académico adecuó los planes de estudio al enfoque de formación por competencias, para ser implementados a partir del año 2011, en el marco del trigésimo aniversario de la UTEC. También elabora los diseños Instruccionales para las asignaturas que ciclo a ciclo se ofrecen con los nuevos planes de estudio. Los otros proyectos se van ejecutando paralelamente a la implantación de los nuevos planes de estudio.

La universidad también ha analizado el alcance de los procesos de grado y, como resultado, ha abierto el espacio de opción para el proceso de graduación, incorporando las preespecialidades, cuyo objetivo central consiste en formar a los estudiantes en aquellas áreas específicas, que son esenciales como herramientas para el inmediato desempeño profesional, así como para superar competencias no logradas.

\section{BIBLIOGRAFÍA.}

Plan de Desarrollo Curricular. 2010. 